\title{
COMMENTARY
}

\section{Dependency of Quality Education for Attaining the Health-related Sustainable Development Goals in Africa}

\author{
Peter A. Okebukola \\ Chairman of Council, Crawford University, Igbesa,Ogun State, Nigeria; former Executive Secretary, National Universities \\ Commission, Nigeria; and Special Adviser to the Vice-Chancellor, University of Medical Sciences, Ondo State, Nigeria \\ *For Correspondence: Email; pokebukola@yahoo.com; Phone: +2348022904422
}

There is a growing body of empirical evidence on the positive relation between education and health $^{1}$. In a 2001 Nigerian National Survey (FGN/UNICEF/UNESCO) (ref), data was provided which confirmed a positive association between schooling and the health status of family members. A positive link was also shown between parental level of education, and schooling received by their children $(\mathrm{r}=0.78 ; \mathrm{p}<.001)$ as well as between health and the sanitation status of family members $(r=0.82 ; \mathrm{p}<.001)$. A positive contribution of schooling to the efficiency of (consumer) choices was also documented. Lastly, a relation between schooling and positive reproductive health behaviours of women was firmly established in the study sample. Although causality is not established, converging findings in Japan $^{2}$, Australia ${ }^{3}$, the $\mathrm{US}^{4}$, Ghana ${ }^{5}$, and in Namibia $^{6}$, suggest an emerging global external validity of the relationships between education and various development outcomes. This commentary examines the potential impact of education as an important and critical outcome for attaining the health-related Sustainable Development Goals (SDGs), especially within the context of subSaharan Africa. It steps back in the opening statements to link poor educational outcomes to the lacklustre performance of African countries in the Millennium Development Goals (MDGs). It proceeds to canvas deeper attention to quality education as a major springboard for achieving the SDGs. The concluding section provides a 4-point plan of action that would ensure better performance for African countries in attaining the health-related SDGs.

Hopes were high in 2006 that Africa will stand up to be counted when the roll of regions which attain at least $50 \%$ of the targets of the Millennium Development Goals (MDGs) is called in December 2015. It was forethought that the launch of Education for All (EFA) on the African continent (in Senegal) in 2001 will propel regional leaders to harness the power of education to address the MDGs especially those relating to health. At the terminal date of the MDGs, over $90 \%$ of African countries faltered. A major stumbling block to the attainment of health-related MDGs in Africa was the high level of illiteracy. The region's average adult literacy rate was 59\% in 2015, with a lower rate for females (51\%) (Please, check this - if $51 \%$ is the rate for females, this cannot be said to be lower rate). Although probably not by design, the proximity of quality education and health in the listing of the SDG themes is not lost on many. Education and health are intertwined and mutually supportive. The link between education and health has long been established. As an example, the positive direct link is shown in communities with high literacy rates recording low maternal and infant mortality rates in a recent US study ${ }^{4}$.

Swinging now to the SDGs and due to lessons from the MDGs, African countries desiring impressive performance on health-related indicators have to laser-focus on delivering quality education to their people. The question that immediately arises is: what is quality education? A preface to the answer is: there are two sides to the education coin- quantity and quality. Quantity is the number of beneficiaries served by the education process. Quality on the other hand is a measure of how the education delivered is fit for purpose. It has to do with the relevance and adequacy of the knowledge, skills, attitudes and values that learners acquire during the course of being educated. Quality education produces citizenry that is able to apply what is learned to solve emerging everyday problems. The 
qualitatively educated is able to take action, and to dissolve some of the challenges relating to such issues as health, environment, food and employment security.

The third and final question is: how can African countries deliver qualitative education to bolster attainment of health-related SDGs especially on reproductive health? A 4-step approach is proposed. First is a doubling of the pace of delivering functional adult literacy. It is not enough to corral villagers under a tree to teach them how to read and write. Embedding knowledge and skills into the curriculum of such literacy classes that will empower men and women to attend, in a practical manner, so that health, environmental, employment and other challenges will be the desired value added. Special curriculum attention should be paid to training young girls and adult women on matters which will promote good reproductive health. High priority should be placed in the curriculum of adult literacy classes on shunning teenage pregnancy as well as basic issues relating to pregnancy, maternal health and childcare. Worth noting is that in 2015, less than $25 \%$ of African adults were served with such functional literacy programmes ${ }^{7}$. To achieve SDGs connected with health, African countries should strive to attain an annual growth rate in functional adult literacy of $5 \%$ over the next 10 years at least.

Second, is teacher training. The teacher is the key agent to effectively deliver the curriculum that will promote good reproductive health. Sadly, teachers across Africa have intolerably low content and pedagogic knowledge and will need significant capacity upgrading. The plan canvassed in this commentary demands that African countries should improve investment in teacher education at all levels. With Nigeria as a case study, the intended scheme is to recruit 500,000 teachers and intensively retrain them to bolster their content and pedagogic knowledge. Government will be prodded to focus training of these teachers in areas which will include better quality delivery of a curriculum that is laced with elements of sound reproductive health practices.

Third is significant improvement in consternation of resourcing for the schooling community including provision of learner-friendly environment; infrastructure notably power and water; research facilities and capacity-building for researchers; and welfare of teachers. On these variables, African countries record paltry performance and will need to invest more to ensure noteworthy improvements in the coming years.

The last in the short list of suggestions is the use of rudimentary mobile technology as lever to deliver quality education. In spite of the dark firmament of illiteracy, the penetration of mobile telephony in Africa lights up the statistics as it is one of the highest in the world. Market women (and men), local artisans, school boys and girls and about $53 \%$ of the citizenry in Africa, on the average, have mobile phones which are largely used for voice calls and text messaging. The agriculture sector in Africa has successfully ridden on the back of mobile telephony to deliver services to rural farmers. The education sector should improve on this delivery platform and mechanism by taking quality education to the rural dwellers. Short messages on good practices in reproductive health should be sent in local languages while radio and TV programmes in these languages support the impact of the mobile technology pathway.

In closing, it should be stressed that generous political will need to be mustered by African leaders to implement these and other suggestions in order to escape the shame of the ignoble list of countries that fail to achieve at least $70 \%$ of the SDGs by 2030 . With corruption ravaging the continent and emergence of selfserving leaders, the outlook is bleak; attaining SDGs will be a greasy pole to climb.

Conflict of Interest : None

\section{References}

1. Okebukola, P.A.O. Nexus among human security indicators. Journal of African Culture and International Understanding, 2014; 8, 20-34.

2. Amira, O. Predictors of health status among the Japanese. Science Scope, 2008; 82 (2), 123-134.

3. Smith, S.T. Education and health. Health Informatics, 2010; 39 (4), 231-266.

4. Johnson, J. Multivariate exploration of education and health indicators. Review of Research in Educational Measurement, 2012; 67 (2), 115-145.

5. Mensah, O. Analysing the importance of education 


\section{Peter A. Okebukola}

Research in Science Education, 2005; 25(2), 88105.

6. Stephen, M. Health and education in Namibia. 2011;

Unpublished project report. University of
Attaining the Health-related SDGs in Africa

Namibia. UNESCO. State of Education in the World. 2015; Paris: UNESCO. 